\title{
Bow Hunter's Syndrome
}

The Neurohospitalist

2018, Vol. 8(3) 160

(C) The Author(s) 2017

Reprints and permission:

sagepub.com/journalsPermissions.nav

DOI: $10.1177 / 1941874417733219$

journals.sagepub.com/home/ $\mathrm{NHO}$

\section{Altaf Saadi, MD', and Joshua P. Klein, MD, PhD ${ }^{2}$}

\section{Keywords}

stroke, vertebral artery dissection, angiography

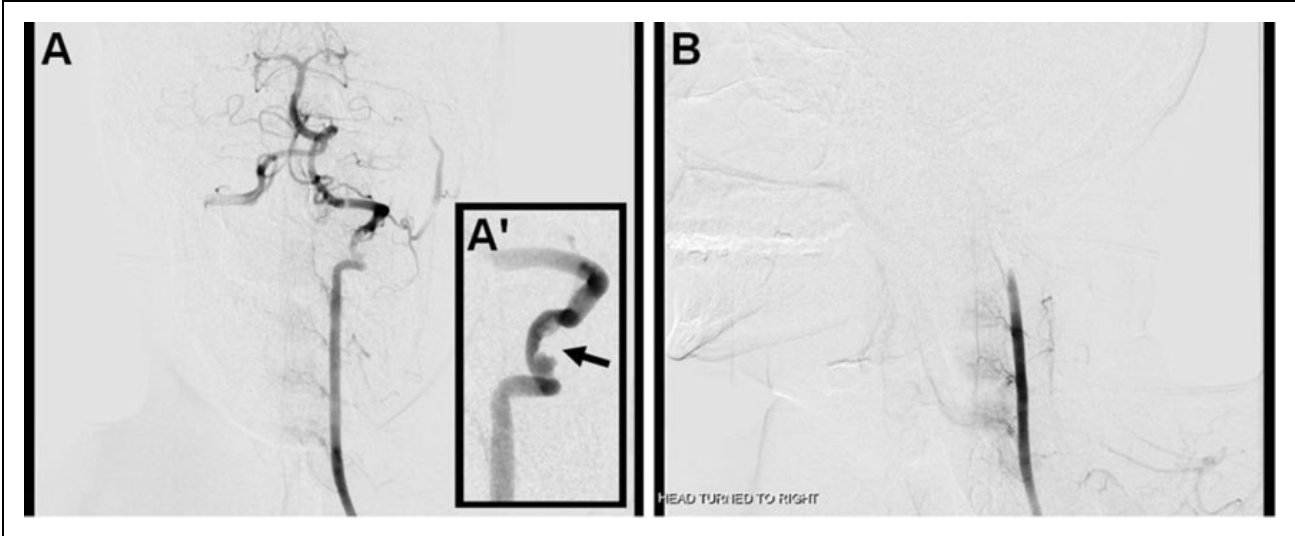

Figure I. Angiography images of the patient with A. non-occlusive left VA dissection and B. complete occlusion of the left VA with rightward head turn.

A 19-year-old male suffered sequential acute ischemic cerebral infarctions in the vertebrobasilar arterial territory, each episode following rigorous exercise with frequent head turning. Angiography revealed a nonocclusive left vertebral artery (VA) dissection near the transverse foramina of $\mathrm{C} 2$ (Figure $1 \mathrm{~A}$ and $\mathrm{A}^{\prime}$ ) and complete occlusion of the left VA at that level with rightward head turn (Figure 1B). The patient was placed in a rigid cervical collar and treated with enoxaparin. Repeat angiography after 3 months showed resolution of the arterial dissection but persistent compression of the left VA with rightward head turn. The patient underwent elective surgical decompression of the left VA, where his neck muscles were found to be hypertrophied. Bow Hunter's syndrome (BHS) refers to mechanical occlusion of the VA during head rotation secondary to numerous etiologies including congenital or acquired bony malformations or neck muscle hypertrophy. ${ }^{1}$ Unrecognized BHS may result in recurrent infarctions, but with decompression surgery can, as in this case, carry an excellent prognosis. ${ }^{2}$

\section{Authors' Note}

Dr Saadi evaluated the patient, gathered the data, conceived the concept and design of the manuscript, and drafted and revised the manuscript for content. Dr Klein evaluated the patient, edited the manuscript, and provided study supervision and coordination. Both authors read and approved the final manuscript.

\section{Declaration of Conflicting Interests}

The authors declared no potential conflicts of interest with respect to the research, authorship, and/or publication of this article.

\section{Funding}

The authors received no financial support for the research, authorship, and/or publication of this article.

\section{References}

1. Jost GF, Daily AT. Bow hunter's syndrome revisited: 2 new cases and literature review of 124 cases. Neurosurg Focus. 2015;38(4): E7. doi:10.3171/2015.1.FOCUS14791.

2. Zaidi HA, Albuquerque FC, Chowdhry SA, Zabramski JM, Ducruet AF, Spetzler RF. Diagnosis and management of Bow Hunter's syndrome: 15-year experience at Barrow Neurological Institute. World Neurosurg. 2014;82(5):733-738.

\footnotetext{
' National Clinical Scholars Program, University of California Los Angeles, Los Angeles, CA, USA

${ }^{2}$ Department of Neurology, Brigham and Women's Hospital, Boston, MA, USA

Corresponding Author:

Altaf Saadi, National Clinical Scholars Program, University of California Los Angeles, 10940 Wilshire Blvd, Los Angeles, CA 90024, USA.

Email: asaadi@mednet.ucla.edu
} 